\title{
ANALYSIS AND SYNTHESIS OF INFLUENCE OF TOOL-ELECTRODE MATERIALS IN ELECTRIC DISCHARGE MACHINING OF M2 HIGH-SPEED TOOL STEEL
}

\author{
CHANDRA MOULI A ${ }^{\mathbf{1}}$, PARAMESWARA RAO CHVS ${ }^{2} \boldsymbol{\&}$ DEVA KUMAR MLS ${ }^{3}$ \\ ${ }^{1}$ Research Scholar, Department of Mechanical Engineering, JNTU Anantapuramu, India \\ ${ }^{2}$ Professor and Principal, Narayana Engineering College, Gudur, India \\ ${ }^{3}$ Professor, Department of Mechanical Engineering, JNTU Anantapuramu, India
}

\begin{abstract}
Molybdenum high-speed steel particularly termed as M2 High-Speed Tool Steel specifically in the manufacture of Milling Cutters, Thread roll Dies, and other emerging areas like automobile, defense, aerospace, bio-medical segments has an extensive applications. Machinability studies for this type of the material are having extreme significance. M2 steel has the higher toughness and inhomogeneity, resulting in decreased machinability. These features of the M2 steel demands an advanced machining process. Electric Discharge Machining (EDM), a versatile process in machining the advanced materials, in which the thermal conductivity and the electrical resistivity of the work piece and the tool electrode plays a key role in determining the performance of the process. In the present work, relative studies has been conducted on the EDM of M2-Steel utilizing two different electrodes namely graphite and copper. Taguchi's $L_{27}$ orthogonal array was utilized to design the experiments. Peak current (IP), pulse-on time (Ton), pulse-off time (Toff), and voltage (V) were selected as the input process parameters. The performance of the machining process is evaluated by measuring the three different responses namely material removal rate (MRR), electrode wear rate (EWR), and surface roughness (SR). The experimental results indicated that the Graphite tool electrode ensued $12.84 \%$ higher MRR,and 11.59\% lower SR than the copper tool electrode. Copper tool electrode resulted in a $3.61 \%$ lesser electrode wear rate (EWR).

KEYWORDS: Electric discharge machining, M2 steel, Material removal rate (MRR), Electrode wear rate (EWR), Surface roughness $(\mathrm{SR})$.
\end{abstract}

Received: Jun 06, 2020; Accepted: Jun 26, 2020; Published: Aug 18, 2020; Paper Id.: IJMPERDJUN2020794

\section{INTRODUCTION}

Machining of Tool steel materials is extremely hard to be machined through traditional machining methods due to their intense hardness and toughness. M2 steel is classified as "medium" machinability tool steel in the annealed condition and its machinability features are less than $50 \%$ in contrast to that of the other hardened tool steel materials which considerably ease in machining. The electric discharge machining (EDM) process has emerged as a useful technique for generating cavities with smaller and close tolerances [1]. Besides, EDM was a proven effective economic method for generating shapes faster with the best accuracy for all electrically conductive materials irrespective of their hardness [2]. EDM is a versatile machining process that has the ability for processing the complex and hard materials without any shape constraints [3]. In this process, the erosion for the work material is occasioned through a sequence of spark discharges in between the tool electrode and work piece as both are submerged in a dielectric medium. In the EDM process, the tool-electrode profile is imitated on the work material. The tool-electrode dimensions are represented in the manner that sparking gap in between work material surface to 
be developed and tool-electrode is needed to be retained.The proper inter-electrode gap needs to be selected for better material removal rate (MRR) and the fine surface features. The process performance is greatly reliant on the tool-electrode material and the electrode tool-design. The simple tool-electrodes are generally made by the traditional processes, whereas the intricately shaped tool-electrodes are developed by the casting, machining and sometimes thermal spraying procedures. The EDM machined is generally controlled through CNC for the tool-electrode progress in machining [4]. The selection of the appropriate electrode crucially influences the machining time, manufacturing costs, surface features and dimensional accuracy. The choice of the tool-electrode material is a vital resolution in the EDM experimentation for die-sinker EDM. The key process responses for the selection of tool-electrode material are MRR, EWR, SR, dimensional accuracy, machinability, and cost of tooling. The features of the various tool-electrode materials and their effect on EDM process performances including the manufacture of tool-electrodes has been summarized in past researches for the EDM process [56]. Conversely, owing to the random behavior of the EDM process, the base for the selected materials is majorly grounded on the data from the experiments. On the other hand, the EDM process is constrained by its relatively lower material removal rates. In the interest of enhancing the process effectiveness, researchers have performed enormous work. The influence of the process parameters under the various types of tool electrode materials such as copper, brass on the qualitative and quantitative responses [7] were analyzed by earlier researchers. The surface features Titanium material processing through EDM using special grade graphite tool electrodes for die-sinker EDM application reported better-enhanced machining responses with graphite [8]. In the later years, the influence of different tool-electrode materials (brass, tungsten-copper and graphite) have been compared for the EDM on the Aluminum LM6 [9]. The authors have reported that higher material erosion and better surfaces are noticed during the application of the graphite electrode [9]. The influence of brass, graphite and copper electrodes on EDM for machining 316 stainless steel for the MRR and SR responses were studied and noticed that the brass electrode performed the copper electrode with finer surfaces [10]. The brass tool performed best followed by the copper tool when different aspects of surface integrity were analyzed [11]. The influence of the different tool electrodes on the EDM of Titanium material was reported to the high MRR achieved by zinc and brass- zinc tool-electrodes in contrast to the copper tool-electrode. Copper exhibited the least tool wear as well as the least recast layer, succeeded by the brass and zinc tool-electrodes [12]. The EDM performance with the tool- electrodes developed by the laser sintering process during EDM of titanium [13] were reported by authors. A review of the literature revealed that numerous work has experimented on the EDM process utilizing the various tool-electrode materials. However, very limited work has reported in the EDM process because of M2 Steel material as work material and copper and graphite as the tool-electrode materials. In the present work, experimentation has done to examine the material removal rate (MRR), electrode wear rate (EWR), and surface roughness (SR) of EDM process for M2 steel considering peak current $\left(I_{P}\right)$, pulse-on time $\left(T_{O N}\right)$, pulse-off time $\left(T_{O F F}\right)$ and voltage (V) as process parameters. Two different electrodes namely copper and graphite were reviewed for this experimentation. Statistical analysis has been performed after the EDM process to identify the key process parameters influencing the machining process.

\section{EXPERIMENTAL PROCEDURE}

\subsection{Materials and Methods}

The experimentation was performed on SPARKONIX-S-35 ZNC (die-sinker) EDM machine. The EDM was performed with cylindrical graphite and copper tool-electrodes of $10 \mathrm{~mm}$ diameter. The chemical composition of $\mathrm{M} 2$ steel is listed in Table 1 and the key properties of the M2 steel and tool-electrodes are listed in Table 2. 
Table 1: Chemical Composition of M2 High-Speed Tool Steel

\begin{tabular}{|c|c|c|c|c|c|c|c|c|c|c|}
\hline Elements & $\mathbf{C}$ & $\mathbf{C r}$ & $\mathbf{W}$ & $\mathbf{M o}$ & $\mathbf{V}$ & $\mathbf{S i}$ & $\mathbf{S}$ & $\mathbf{P}$ & $\mathbf{M n}$ & $\mathbf{F e}$ \\
\hline Weightin \% & 0.9 & 4.1 & 6.1 & 4.92 & 1.78 & 0.38 & 0.001 & 0.025 & 0.25 & Balance \\
\hline
\end{tabular}

Table 2: Properties of Work piece and Tool-Electrodes

\begin{tabular}{|l|c|c|c|}
\hline \multirow{2}{*}{\multicolumn{1}{c|}{ Material }} & \multicolumn{3}{c|}{ Properties } \\
\cline { 2 - 4 } & Density (g/cm3) & Melting Point (oC) & Thermal Conductivity (W/m.k) \\
\hline M2 High Speed Tool Steel & 8.138 & 4680 & 41.5 \\
\hline Copper & 8.960 & 1084 & 401 \\
\hline Graphite & 2.26 & 3600 & 98 \\
\hline
\end{tabular}

\subsection{Process Parameters and Experimental Planning}

The EDM process parameters nominated in the present work are peak current, pulse-on time, pulse-off time and voltage. The performance measures nominated are material removal rate (MRR), electrode wear rate (EWR), and surface roughness (SR). The selected process parameter and their levels were listed in Table 3. The experimentation has been performed on the Sparkonix S-35 EDM Machine represented in Figure 1. The experimentation is performed with three levels and four factors utilizing the design of experiments (DOE) methodology by selecting a three-level orthogonal array (OA) $L_{27}$. Taguchi designs confer to the experimental design as 'off-line quality control'. A total of 27 experiments $\left(L_{27}\right)$ have been performed with graphite and copper electrodes. The selected graphite and copper tool materials were shown in Figure 2 and Figure 3 respectively for the machining process. The MRR and EWR were calculated by using Eqn. (1) and Eqn. (2) respectively.

Table 3: Process Parameters and their Levels for Machining

\begin{tabular}{|l|c|c|c|c|c|}
\hline \multicolumn{6}{|c|}{ Process Parameters } \\
\hline \multirow{2}{*}{ Parameter } & \multirow{2}{*}{ Symbol } & \multirow{2}{*}{ Units } & \multicolumn{3}{c|}{ Levels } \\
\cline { 4 - 6 } & & Low & Medium & High \\
\hline Peak Current & $I_{P}$ & $\mathrm{~A}$ & 10 & 20 & 30 \\
\hline Pulse-on Time & $T_{O N}$ & $\mu \mathrm{s}$ & 100 & 200 & 300 \\
\hline Pulse-off Time & $T_{O F F}$ & $\mu \mathrm{s}$ & 20 & 30 & 40 \\
\hline Voltage & $V$ & $\mathrm{~V}$ & 15 & 25 & 35 \\
\hline
\end{tabular}

$M R R=\frac{\text { Volume of the work material eroded }}{\text { Time }} \mathrm{mm}^{3} / \mathrm{min}$

$E W R=\frac{W_{b}-W_{a}}{\text { Time } * \text { Density }} \mathrm{mm}^{3} / \mathrm{min}$

Where $W_{b}=$ Weight of the electrode before machining

$W_{a}=$ Weight of the electrode after machining 


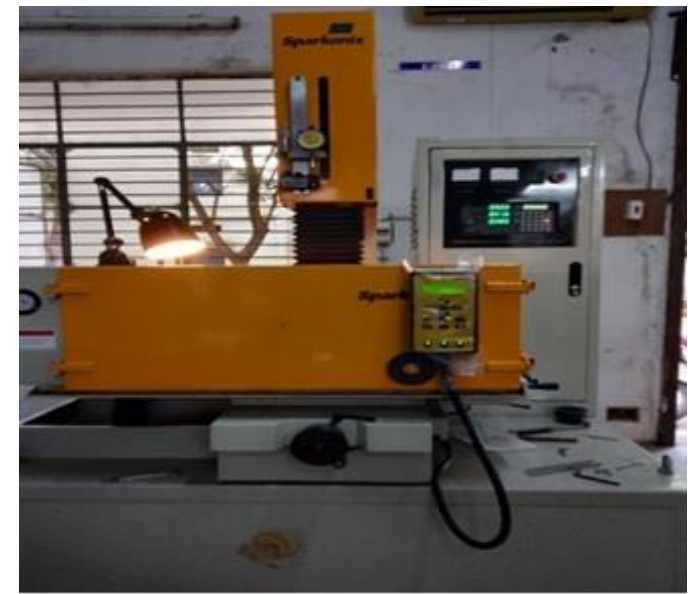

Figure 1: Die-Sinker EDM Machine (Make: Sparkonix S-35)

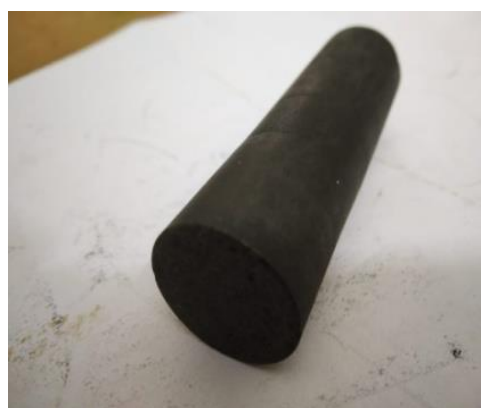

Figure 2: Graphite Electrode

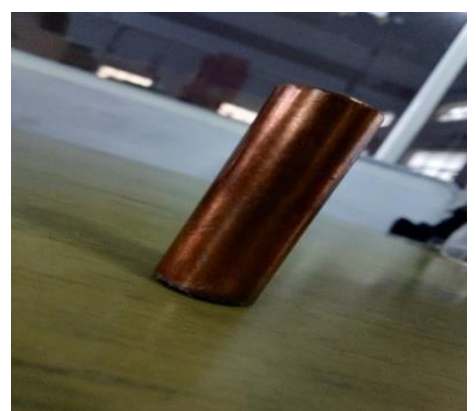

Figure 3: Copper Electrode

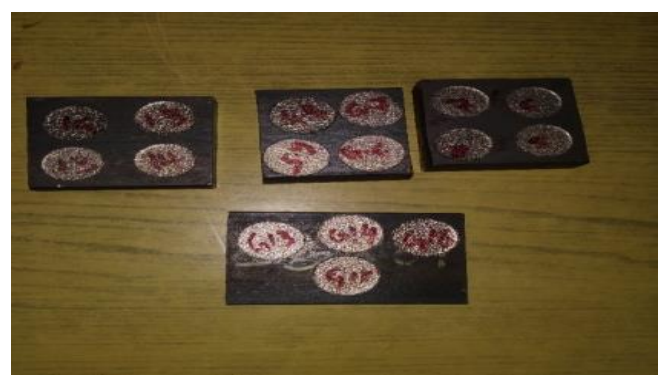

Figure 4: M2 High-Speed Tool Steel Specimen after Machining

\section{RESULTS AND DISCUSSIONS}

The Machined samples of M2 high-speed tool steel is shown in Figure 4. The results are discussed in this section.

\subsection{Influence of Process Parameters on Material Removal Rate}

The influence of different process parameters such as peak current $\left(I_{P}\right)$, pulse-on time $\left(T_{O N}\right)$, pulse-off time $\left(T_{O F F}\right)$, and voltage $(V)$ on MRR are represented in Figure 5. 


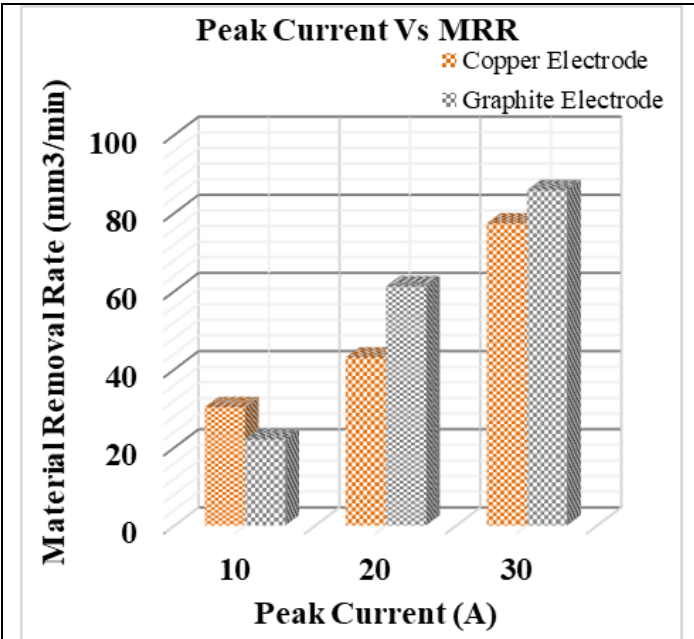

Figure 5(a): Peak Current Vs. MRR

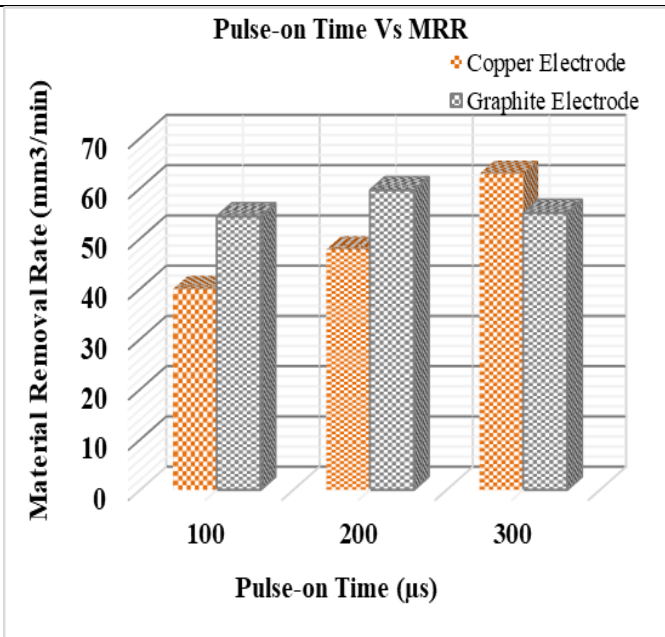

Figure 5(b): Pulse-on Time Vs. MRR

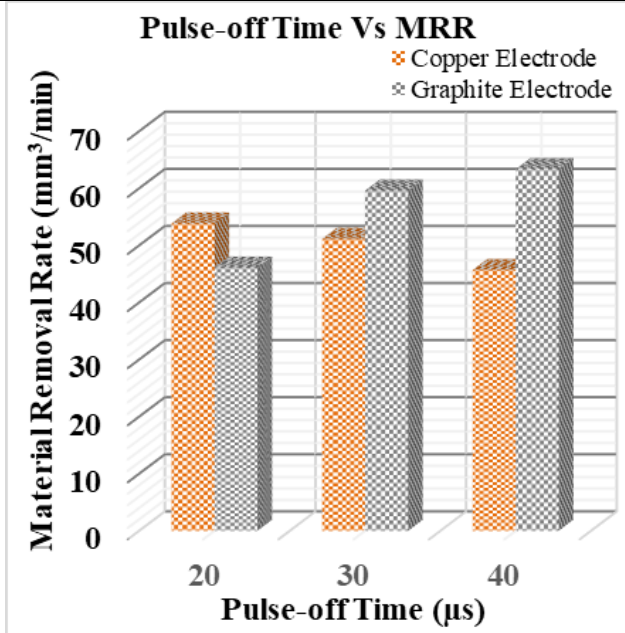

Figure 5(c). Pulse-off Time Vs. MRR

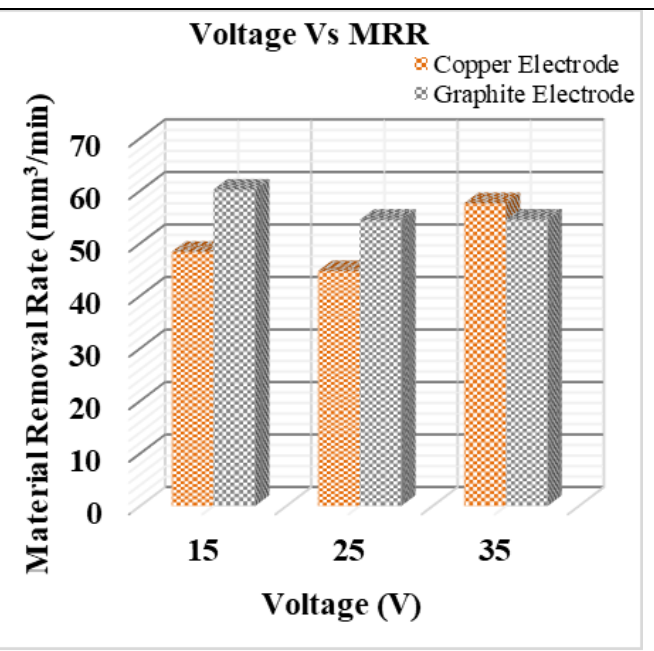

Figure 5(d). Voltage Vs. MRR

Figure 5: Influence of Process Parameters on Material Removal Rate (MRR)

Results from Fig.5(a) shows that the peak current $\left(I_{P}\right)$ is directly related to MRR. This phenomenon is associated with the reason that an increasing peak current $\left(I_{P}\right)$ generates intensified sparks that produce the high temperatures, in turn occasioning moremelting and erosion from the work piece. Similar trends have been noticed with both copper and graphite electrodes. The copper electrode cannot sustain a high current density. So material removal rate (MRR) is limited. Further, the remaining factors could not affect MRR considerably as compared to the peak current. Results from Figure 5(b) shows that MRR has increased with $T_{O N}$ up to a threshold limit of $100 \mu$ s to $200 \mu$ s, and thereafter MRR decreased considerably. It is noticed from Fig.5(c) that MRR tends to decreases continuously with the increase of pulse-off time for copper electrode, whereas pulse-off time shown the least significant influence in the case of the graphite electrode. This could be occasioned for the reason that an increase in the $T_{O F F}$, the temperature of the electrode tends to decrease noticeably. Results from Figure 5(d) indicate that with the increase in voltage (V), MRR tends to decrease initially and increase consecutively, for copper tool, whereas for the graphite tool MRR tends to increase consequently for the increase in voltage $(V)$. This in turn occasions in the decrease of MRR. Results from Figure 5(d) shows that MRR has no significant effect on the copper electrode, whereas 
the gradually decreased in the application of the graphite electrode. The Taguchi based mathematical relation for correlating the MRR and the process parameters for the copper and graphite electrodes is shown the Eqn. (3) and Eqn. (4) respectively.

$$
\begin{aligned}
M R R_{\text {Copper }}= & 78.5-2.745\left(I_{P}\right)+0.0383\left(T_{\text {ON }}\right)-0.407\left(T_{\text {OFF }}\right)-3.68(V)-0.1083\left(I_{P}{ }^{2}\right)+0.00828\left(V^{2}\right) \\
& +0.00382\left(I_{P}\right)\left(T_{\text {ON }}\right) \\
M R R_{\text {Graphite }}=- & 30.8+4.77\left(I_{P}\right)-0.030\left(T_{\text {OFF }}\right)-0.0729\left(I_{P}{ }^{2}\right)+0.0447\left(I_{P}\right) *\left(T_{\text {OFF }}\right)
\end{aligned}
$$

\subsection{Influence of Process Parameters on Electrode Wear Rate}

It is very important to analyze the tool wear in the EDM process, which ultimately determines the tooling costs associated with the machining process.

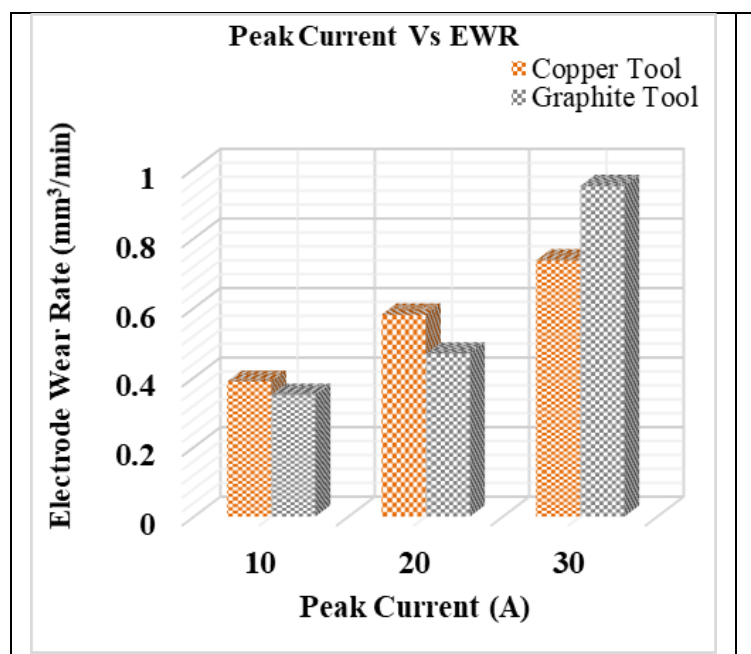

Figure 6(a): Peak Current Vs. EWR

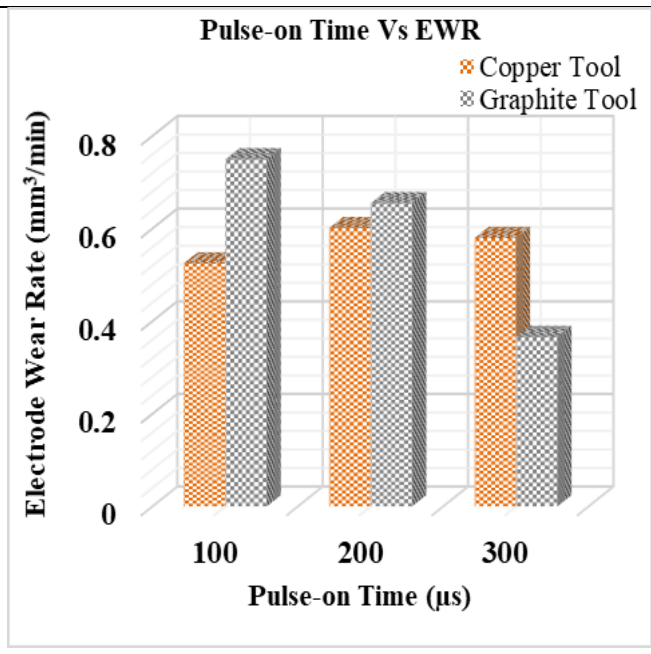

Figure 6(b): Pulse-on Time Vs. EWR

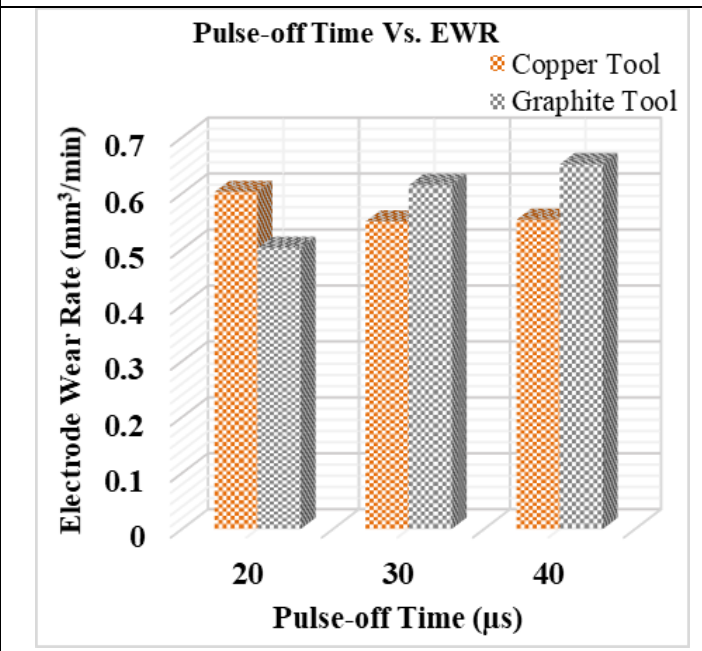

Figure 6(c). Pulse-off Time Vs. EWR

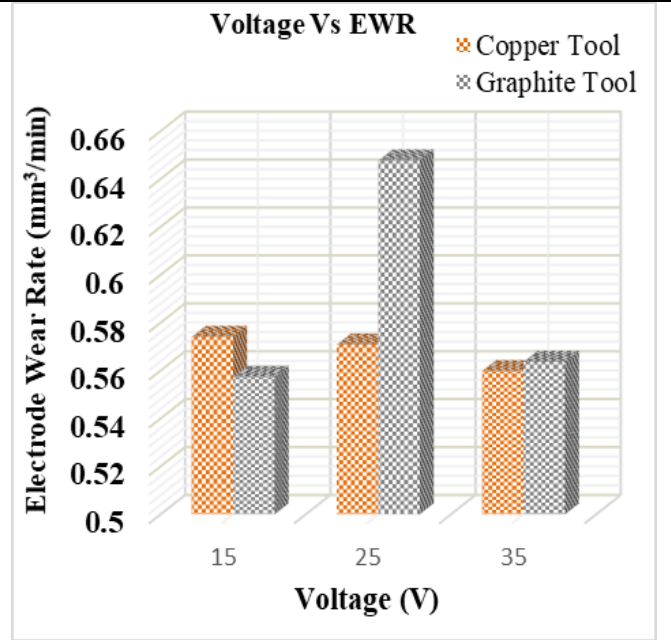

Figure 6(d). Voltage Vs. EWR

Figure 6: Influence of Process Parameters on Electrode Wear Rate (EWR)

Figure 6(a) reflects the influence of peak current on EWR for copper and graphite electrodes. The EWR is noticeably high for the instanceof the copper electrode as compared to that of the graphite electrode. It has been noticed EWR of very 
negligible as less than $1 \%$ with the graphite electrode, for all the instances of peak current. For instance, at $T_{O N}=100 \mu \mathrm{s}$, it has been noticed higher electrode wear, increased EWR noticed 9.89\% ( $\left.I_{P}=10 \mathrm{~A}\right), 19.29 \%\left(I_{P}=20 \mathrm{~A}\right)$, and $29.09 \%$ lesser $\left(I_{P}=30 \mathrm{~A}\right)$ for copper electrode as compared to that of graphite. The experimentation has been performed with straight polarity (i.e. tool-electrode is cathode and work piece is anode), where the flow of electrons from the tool-electrode liberates intense energy on the surface of tool and work piece, which may cause tool-electrode erosion. It is also noticed that the magnitude of EWR depends on the choice of tool-electrode materials as well as discharge energy. The greater the melting point of tool-electrode material will result in low erosion from the electrode. As the copper tool melting point $\left(1084^{\circ} \mathrm{C}\right)$ which is far less as compared to that of graphite-tool $\left(3600^{\circ} \mathrm{C}\right)$, this occurrence is more for copper- electrode at low $I_{P}(10 \mathrm{~A}$ and 20 A). Figure 6(b) represents the influence of pulse-on time on EWR. It can be noticed that EWR tends to decrease with the increase in $T_{O N}$ for both copper and graphite electrodes. It has been observed that EWR for graphite electrode is higher up to $T_{O N}=200 \mu \mathrm{s}$ and at higher $T_{O N}(300 \mu \mathrm{s})$ the copper electrode noticed higher EWR. Results from Figure 6(c) represents the copper electrode has high EWR $\left(T_{O N}=20 \mu \mathrm{s}\right)$ and the graphite electrode witnessed higher EWR $\left(200 \mu \mathrm{s} \leq T_{O N} \leq 300 \mu \mathrm{s}\right)$. Results from Figure 6(d) shows the influence of voltage on the EWR. It has been witnessed that the voltage factor is having the least influence on the EWR. It is also noticed that EWR is least sensitive to $T_{O N}$. The likely reason is that copper-tool is thebest heat conductor as compared to that of graphite (Thermal conductivity of copper is $401 \mathrm{~W} / \mathrm{m} \mathrm{K}$, whereas for graphite is $98 \mathrm{~W} / \mathrm{m} \mathrm{K}$ ), extended pulse-on time occasioned in the decrease of temperature at the tool-electrode surface, which in turn resulted in lesser EWR. The Taguchi based mathematical equation for correlating the EWR and the process parameters for the copper and graphite electrodes are listed in the Eqn. (5) and Eqn. (6) respectively.

$$
\begin{gathered}
E W R_{\text {Copper }}=0.186+0.0298\left(I_{P}{ }^{2}\right)+0.000568\left(T_{O N}\right)-0.00924 T_{O F F}+0.00891(V)-0.000005\left(T_{O N}{ }^{2}\right)+ \\
0.00032\left(I_{P}\right)\left(T_{O N}\right)-0.00481\left(I_{P}\right)(V)+0.000034\left(T_{O N}\right)\left(T_{O F F}\right)
\end{gathered}
$$

$$
E W R_{\text {Graphite }}=0.753-0.0426\left(I_{P}\right)-0.001917\left(T_{\text {ON }}\right)+0.00748\left(T_{\text {OFF }}\right)+0.001816\left(I_{P}{ }^{2}\right)
$$

\subsection{Influence of Process Parameters on Surface Roughness}

Surface roughness (SR) is directly related with the roughness average of the machined surfaces in the EDM process. Always the low SR values are preferred from the precision and accuracy point off view. $\mathrm{R}_{\mathrm{a}}$ is the arithmetic average of the absolute values of the profile height deviations from the mean line, recorded within the evaluation length. Simply put, $R_{a}$ is the average of a set of individual measurements of surface peaks and valleys. Reveal the Ra formula for more insight.The mean average of SR of the EDM'ed surface is measured by roughness tester (Make: Talysurf S-3+). Results depicted in Figure 7 represents the influence of process parameters on surface roughness. Figure 7(a) represents the trends of responses for SR values under the effect of peak-current for copper and graphite electrodes. Peak current is responsible for the high intense spark striking on the work piece with at high peak-current occasioning the higher material erosion owing to the developed impact forces. This in turn results in the increased energy penetration in the work material surface that ultimatelyconsequences in wider and deeper crater formation, resulting in a rougher surface [16]. Figure 7(b) represents the responses for the effect of $T_{O N}$ on the SR. The higher sparking times prolong the material melting and vaporization phenomenon, which in turn occasioned on the increase of SR owing to the deep crater formation. The graphite electrode is less vulnerable under thermal shocks. Figure 7(c) shows the influence of $T_{O F F}$ on the performance of SR. It can be witnessed that $T_{O F F}$ influence on the SR is for only a limited. Graphite electrode can allow high current density and thus MRR can be enhanced easily. Figure 7(d) represents the 
developments for SR in the effect of voltage parameters. On the other hand, the low SR for the graphite electrode is occasioned to less energy density owing to the stable sparking cycles as compared to that of the copper electrode. On an average at all levels the graphite electrode outperformed the copper tool in the view of surface roughness for EDM. The Taguchi based mathematical correlation for the SR and the process parameters for the copper and graphite electrodes are shown the Eqn. (7) and Eqn. (8) respectively.

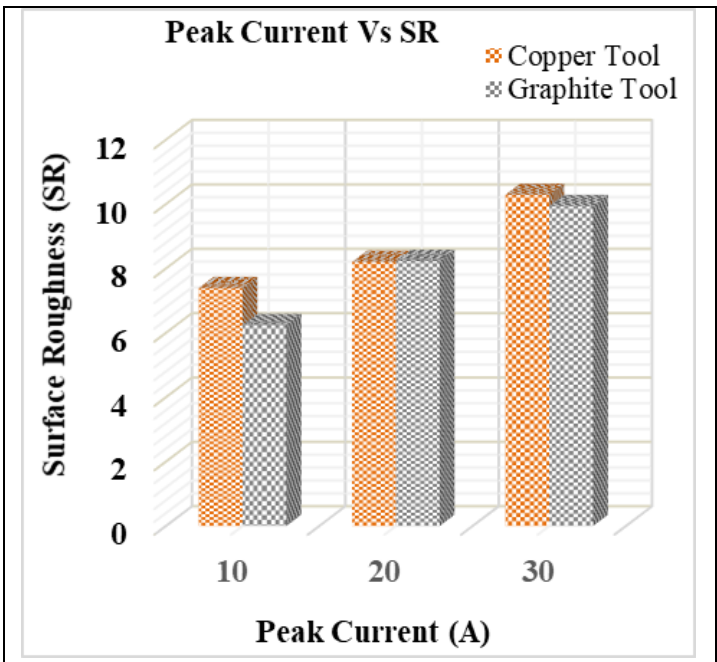

Figure 7(a). Peak Current Vs. SR

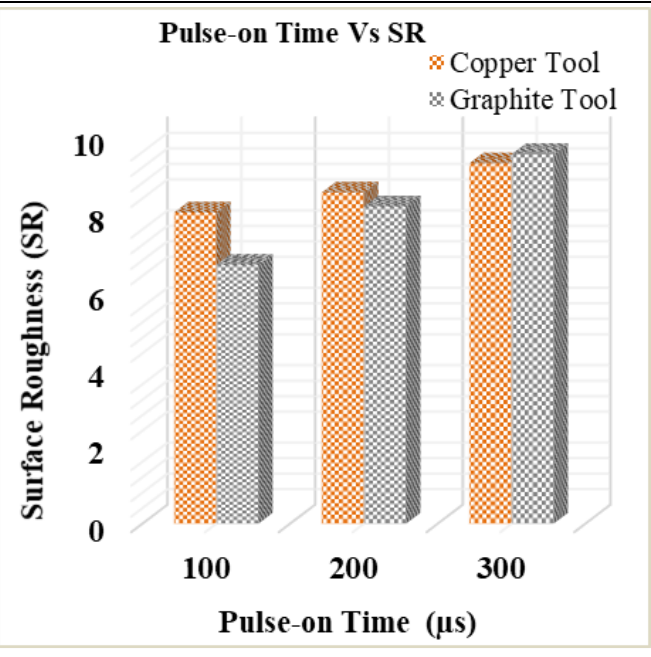

Figure 7(b). Pulse-on Time Vs. SR

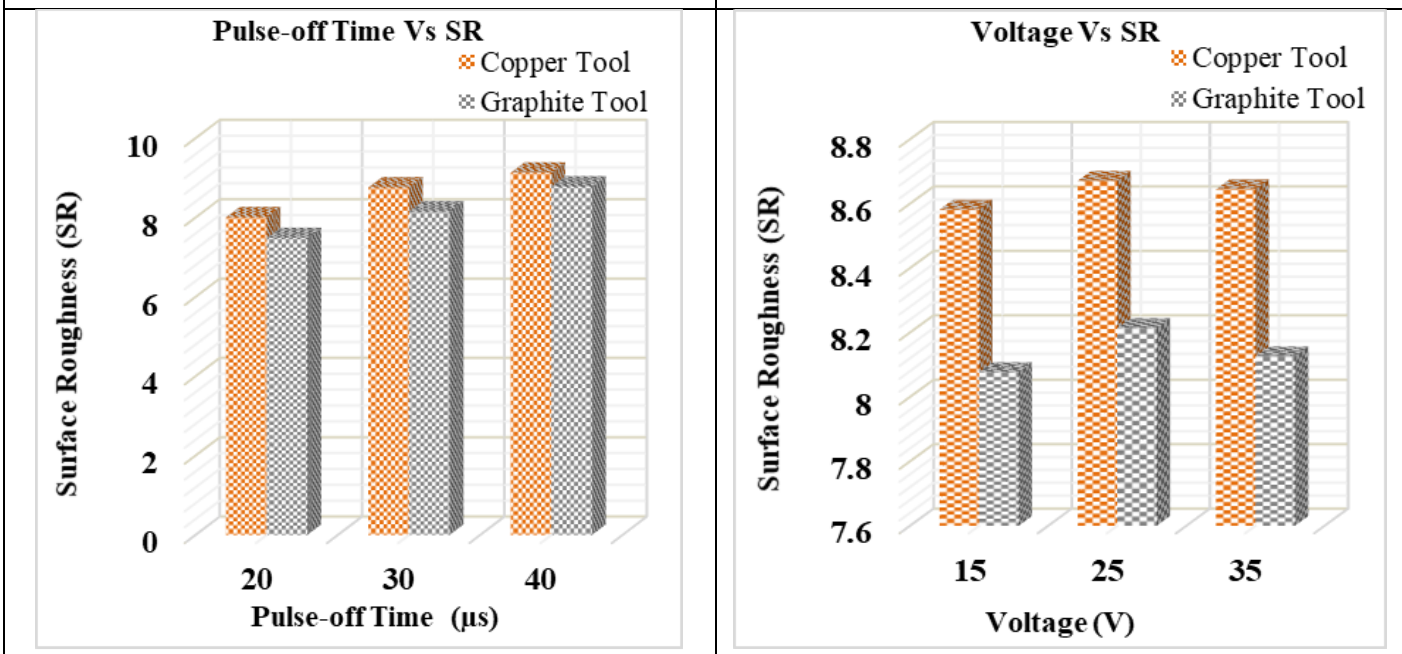

Figure 7(c). Pulse-off Time Vs. SR

Figure 7(d). Voltage Vs. SR

Figure 7: Influence of Process Parameters on Electrode Wear Rate (EWR)

$$
\begin{gathered}
S R_{\text {Copper }}=8.24-0.1105\left(I_{P}\right)+0.0064\left(T_{\text {ON }}\right)-0.0196\left(T_{\text {OFF }}\right)-0.13333(V)+0.00639\left(I_{P}{ }^{2}\right)+0.000228\left(T_{\text {ON }}\right) \\
*(V)+0.00302\left(T_{\text {OFF }}\right) *(V) \\
S R_{\text {Graphite }}=3.13+0.1848\left(I_{P}\right)+0.01429\left(T_{\text {ON }}\right)-0.0535\left(T_{\text {OFF }}\right)-0.1397(V)+0.00474\left(T_{\text {OFF }}\right) \\
*(V)
\end{gathered}
$$

\section{CONCLUSIONS}


The present work has confined to the experimentation on the performance comparison of two different electrodes namely copper and graphite during electric discharge machining (EDM) of M2 High-Speed Tool Steel by Taguchi design of experiments. It has been examined the key EDM process parameters like peak current $\left(I_{P}\right)$, pulse-on time $\left(T_{O N}\right)$, pulse-off time $\left(T_{O F F}\right)$, and voltage $(V)$. Results from present work have arrived at the following conclusions:

- Graphite electrode exhibited a $12.84 \%$ higher material removal rate (MRR)more than that of the copper electrode. The highest MRR $\left(104.958 \mathrm{~mm}^{3} / \mathrm{min}\right)$ is attained at achieved at $I_{P}=30 \mathrm{~A}, T_{O N}=200 \mu \mathrm{s}, T_{O F F}=40 \mu \mathrm{s}$, and V $=35 \mathrm{~V}$.

- Copper electrode outperformed graphite electrode by 3.61\% less EWR. Copper electrode Peak-current and pulseon time are identified as the key process parameters influencing the MRR and SR, whereas pulse-off time and voltage factors have the limited influence on MRR and SR. But in some instances like low values of peak-current (10 A) higher pulse-on time (300 $\mu$ s), the graphite electrode performed better than copper.

- Graphite electrode outperformed the copper tool electrode by $11.59 \%$ in the view of SR by generating fine surfaces. The Melting point of graphite is more than three times higher than that of copper. Thus it tends to retain its form even at high EDM temperature.

- The present work could assist in categorizing the substantial factors that are competently controlled to timeconsumption, minimize the errors, and other qualitative features. This work could deliver the prospective researchers and EDM industries some actual guidelines to opt specific process parameter for attaining the anticipated MRR, EWR and SR in the EDM of M2 High-Speed Tool Steel.

\section{REFERENCES}

1. Lin, Y. C., \& Lee, H. S. (2009). Optimization of machining parameters using magnetic-force-assisted EDM based on gray relational analysis. The International Journal of Advanced Manufacturing Technology, 42(11-12), 1052.

2. Pellicer, N., Ciurana, J., \&Ozel, T. (2009). Influence of process parameters and electrode geometry on feature micro-accuracy in electro discharge machining of tool steel. Materials and Manufacturing processes, 24(12), 1282-1289.

3. Taur, P. G., and S. A. Sonawane. "ANALYSIS OF WEAR RESISTANCE OF TOOL STEEL AFTER DEEP CRYOGENIC TREATMENT." International Journal of Mechanical and Production Engineering Research and Development (IJMPERD) 5. 1, Feb 2015, 11-24

4. Viswanth, V. S., Ramanujam, R., \&Rajyalakshmi, G. (2018). A review of research scope on sustainable and eco-friendly electrical discharge machining (E-EDM). Materials Today: Proceedings, 5(5), 12525-12533.

5. Jeong, Y. H., \& Min, B. K. (2007). Geometry prediction of EDM-drilled holes and tool electrode shapes of micro-EDM process using simulation. International Journal of Machine Tools and Manufacture, 47(12-13), 1817-1826.

6. Nayak, Naveen Kumar, and HARSIMRAN SINGH SODHI. "Optimization of Cnc Turning Parameters for Al-606I Using Response Surface Methodology." International Journal of Mechanical and Production Engineering Research and Development (IJMPERD) 7.4 (2017): 127-138.

7. Sahu, A. K., \&Mahapatra, S. S. (2020). Performance analysis of tool electrode prepared through laser sintering process during electrical discharge machining of titanium. The International Journal of Advanced Manufacturing Technology, 106(3-4), 10171041.

8. Haron, C. C., Ghani, J. A., Burhanuddin, Y., Seong, Y. K., \&Swee, C. Y. (2008). Copper and graphite electrodes performance 
in electrical-discharge machining of XW42 tool steel. journal of materials processing technology, 201(1-3), 570-573.

9. Khan, A. A. (2008). Electrode wear and material removal rate during EDM of aluminum and mild steel using copper and brass electrodes. The International Journal of Advanced Manufacturing Technology, 39(5-6), 482-487.

10. MATARNEH, MOHAMMAD ESSA. "Improvement of abrasive and edge cutting machining efficiency through theoretical analysis of physical conditions." Int. J. Mech. Prod. Eng. Res. Dev 8.2 (2018): 249-262.

11. Amorim, F. L., Stedile, L. J., Torres, R. D., Soares, P. C., \& Laurindo, C. A. H. (2014). Performance and surface integrity of Ti6Al4V after sinking EDM with special graphite electrodes. Journal of materials engineering and performance, 23(4), 14801488.

12. Ali, M. M., Laily, S., Manshoor, B., Syahrian, N., Izamshah, R., Hadzley, M., \& Muhamad, M. (2015). Performance of copper, copper tungsten, graphite and brass electrode on MRR, EWR and SR of aluminium LM6 in EDM die sinking. Journal of Advanced Research in Applied Mechanics, 6(1), 30-36.

13. Choudhary, S., Kant, K., \& Saini, P. (2013). Analysis of MRR and SR with different electrode for SS 316 on die-sinking EDM using Taguchi technique. Global Journal of Research In Engineering. 13(1), 8-13.

14. Dewangan, S., Biswas, C. K., \&Gangopadhyay, S. (2014). Influence of different tool electrode materials on EDMed surface integrity of AISI P20 tool steel. Materials and Manufacturing Processes, 29(11-12), 1387-1394.

15. Bhaumik, M., \&Maity, K. (2018). Effect of different tool materials during EDM performance of titanium grade 6 alloy. Engineering Science and Technology, an International Journal, 21(3), 507-516.

16. Sahu, A. K., \&Mahapatra, S. S. (2020). Performance analysis of tool electrode prepared through laser sintering process during electrical discharge machining of titanium. The International Journal of Advanced Manufacturing Technology, 106(3-4), 10171041.

17. Viswanth, V. S., Ramanujam, R., \&Rajyalakshmi, G. (2020). Performance study of eco-friendly dielectric in EDM of AISI 2507 super duplex steel using Taguchi-fuzzy TOPSIS approach. International Journal of Productivity and Quality Management, 29(4), 518-541.

18. Ghoreishi, M., \&Tabari, C. (2007). Investigation into the effect of voltage excitation of pre-ignition spark pulse on the electrodischarge machining (EDM) process. Materials and Manufacturing Processes, 22(7-8), 833-841.

19. Viswanth, V. S., Ramanujam, R., \&Rajyalakshmi, G. (2020). A Novel MCDM Approach for Process Parameters Optimization in Eco-Friendly EDM of AISI 2507 Super Duplex Stainless Steel.Journal of Advanced Research in Dynamical and Control Systems, 10(7), 54-64. 